\title{
Gender and University Teaching
}

\section{Mousa A}

Higher Institute of Medical Professions, Tripoli, Libyan Arab Jamahiriya

“Corresponding author: Mousa A, Higher Institute of Medical Professions, Tripoli, Libyan Arab Jamahiriya, Tel: +218214627901; E-mail: ajawad2008@gmail.com

Received date: April 23, 2016; Accepted date: May 25, 2016; Published date: May 31, 2016

Copyright: (C) 2016 Mousa A. This is an open-access article distributed under the terms of the Creative Commons Attribution License, which permits unrestricted use, distribution, and reproduction in any medium, provided the original author and source are credited.

\begin{abstract}
Research has found that the rate of female students is higher than the rate of male students. Where this level will change in the work as teaching in the university level.

These facts about women in the university could affect the academic movement and can result in a stereotype that women are always behind, and this sometimes makes a women work very aggressively to present her effort, which can also have a negative effect.

The main idea of this paper is to introduce women in the university setting and answer some questions related, such as has feminization reduced the professional status of teaching? Do Teacher-Student Interactions Vary As a Function of Student Sex?

The study showed that there is a gender stereotype in the level of academic setting that make female students and female teachers feel that male receive more tension and care, and this occurred clearly in different cultures such as Arabic countries and America.
\end{abstract}

Keywords: Gender; Feminism; Masculinity; Female faculty; Evaluation

\section{Introduction}

Can females teaching in the university transform academic structure?

Research has found that women are receiving more doctoral degrees than men, and women are dominant on campus. The research also shows that about 58 percent of the nation's about 13 million undergraduates are female students [1].

Even though the number of females is higher on campus, the actual number of tenured female assistant professors who become associate professors is less than the number of men who achieve this goal [2].

Also, Valian proved by his findings that women progress in parttime positions in the university more slowly than men, and they receive fewer awards and prizes compared to men [3].

Some changes did occur after the feminist movement with regard to authority and the institutions of the academic sector, however. For instance, in 1969 there were only 16 women's studies course syllabi in the United States, whereas in 1982 there were some 20,000 courses and 450 certificate or degree-granting programs. However, although there were well over 600 academic women's studies programs in $2004[4,5]$, the masculine ethic still dominates the academic structure.

These facts about women in the university could affect the academic movement and can result in a stereotype that women are always behind, and this sometimes makes a women work very aggressively to present her effort, which can also have a negative effect.
The main idea of the paper is to study the major factors that related to the feminist structure in the university level.

\section{The Ideal Professor}

Students usually expect their professors to reflect gender stereotypes.

Many studies have found that students are judging their professors based on stereotypes. Rubin found that students identified the ideal professor on the basis of knowledge/intellect/ability, professionalism, ability to communicate, openness, and nurturing.

Other studies have reported similar findings, such as Bennett's [6] study college students' responses about the quality of their professor according to many characteristics.

For instance: a warm interpersonal style, personal charisma, selfassurance, and professionalism in instructional approach were seen as central attributes of instructors. Another study by Downs et al. [7], examined the behaviors that reflect a teacher's competence (e.g., clarity, knowledge ability), control of the classroom, the quality of interaction and participation in and out of the classroom (e.g., availability, feedback, humor), and affect reflecting concern and support for students' needs. These studies found that the ideal teacher embodies some characteristics judged as stereotypically male such as professionalism and control, as well as those that are stereotypically female, such as nurturing, understanding and warmth.

\section{Teacher gender}

Is most important that gender of teacher is affected the student's reflection about the teacher performance and how this related to the evaluation of teachers. Many studies have support this such as [8-10]. 


\section{Individual student and teacher factors}

Student behavior, students achievement and students race consider an individual students factors that affect the interactions between students and their teacher. I think this factor is partial to cultural aspects that differentiate between race to race, which majority of races are supporting the masculine dominate in University teaching.

\section{Gender and the Evaluation of Teaching}

Evaluation is a main point that students can judge their teachers based on gender criteria. In fact, reliance upon student evaluations has been steadily increasing.

Seldin [11] found from his survey that of the academic deans of all 598 of the 740 non-university- related undergraduate liberal arts colleges in the Higher Education Directory of 1997 that responded regarding their practices for evaluating faculty, about 97 percent identified classroom teaching as a major factor in evaluating overall faculty performance at their institutions.

Increasingly, administrators are assessing classroom performance through the use of quantitative student ratings: 88.1 percent reported that they "always used" systematic student ratings of teaching in evaluating teachers, up from 80.3 percent in 1988 and only 54.8 percent in 1978.

The only two papers by Kenneth Feldman [12,13] supported this claim, and they report separate meta-analyses of experimental studies and studies of students' evaluations of actual professors. Feldman conducted a study and found that there were direct effects of gender on evaluation which favored women over men when they evaluated actual professors.

\section{Personnel decisions might raise the following question:}

(How) does gender enter into students' evaluations of their teachers?

In a research review on the evaluation of teaching, researchers concluded that gender is not a critical factor in the process [12-15].

Gender could be the dominant cause in other factors. For instance, that the men are more vulnerable when women's professional role is evaluated. Another reason that makes students rate professors according to their gender is cultural background. Arbuckle et al. [16], for instance, concluded that when college students rate faculty by male and female, ratings are influenced by culturally conditioned gender stereotypes.

Other studies suggested different reasons for rating one gender higher than another. For instance, Basow [17] found a high rating for female professors ranked by male students and a low rating for female professors ranked by female students.

Basow [17] also found that male professors were rated higher in "knowledge of subject matter" compared with female professors regardless of student sex; however, male students more often rate female professors low on an overall measure plus lower ratings on fairness and "thought stimulation".

Basow [18] also found traditional attitudes toward women more common among male students, and that they gave more genderstereotypic ratings of professors than female students, which supports, the congruity theory.

It has observed that a "shifting standards" model used in evaluating male and female professors can be influenced by gender stereotype.
Also, Sprague et al. found that students associated desirable characteristics in a college professor with an unspecified sex as characteristics for the specified "male" professor. For example, college students attributed similar enviable characteristics to a professor named "Dr. Lawson" as they did to a professor named "Sam," the male professor, and so far, different desirable characteristics for a professor named "Sarah," the female professor.

\section{Student Responses to Male and Female Faculty}

According to the model of the ideal professor, student responses to male and female faculty are similar when students do not have perceptions that are influenced by traditional gender roles. In reality, research finds no or few studies that prove differences in students' assessments of male and female faculty in experimental research and in the actual data gathered in end-term evaluations $[12,13]$.

Studies show that to have a full representation of all dimensions, there should be sensitive measurements to promote diminutions or particular teaching methods [19].

Feldman [12] found that the level of the class and the progress can cause student evaluations of female teacher to be slightly higher than for males. The influencing factor is consistent with a more "nurturing" approach.

Also, other studies indicate that the connection between students' evaluations and gender is based on complicated relationships, and this contrasts with other studies that relate that to the initial thought.

Moreover, previous studies [12,20] have not considered the strength of gender schema held by students and instead relate the evaluation of instructors across all students. Based on various researches on gender schema, schema can vary in their complexity or the rigidity with which they are held. It has found more support for masculine gender schema in males. These males hold more traditional stereotypes about women, implying that this could be an important factor affecting this group's evaluations of female professors.

\section{Has feminization reduced the professional status of teaching?}

The question of whether feminization has reduced the professional status of teaching is a difficult one to answer for a number of reasons. First, there is considerable divergence in the literature on what is denoted by the term 'profession' itself. Second, the question assumes that, at some point in history, there was a high proportion of men in the profession and that it enjoyed high status in society.

This may be true in some countries but it is certainly not true in all. Third, the question implies that an enhancement of the professional standing of teaching will result in an increase in the proportion of men in it. Fourth, the question itself raises further questions about the status of women in society as a whole. If a high proportion of women in teaching, or any other occupation is sufficient to reduce its status, what does this reveal about the society itself?

\section{Do Teacher-Student Interactions Vary As a Function of Student Sex?}

Comparing with female, men student have more interaction and more frequent responded to their teachers in all aspects as noticed from many previous research $[8,10,21]$. Teachers also are likely more accepting of male dominance in the classroom, and these differences depend on the teacher sex. 
Page 3 of 4

Becker [22] found that male students engaged to the conversation with their teachers' more than female students. These findings are similar to those of She [23], who found that the majority of teacherinitiated interactions engage male students.

She [23] found from the Brophy-Good Dyadic Child Interaction System, that of 355 teacher-initiated questions, $78.7 \%$ from boys responded to the questions, given a 50:50 sex distribution in the class.

It also found that teachers ask more questions of boys comparing with girls (60.7\%and 39.3\%, respectively). As well Becker [22], also Sikes [24] found that more open and process questions are asked to boys significantly from their teacher than girls do.

Hall et al. [25], found that approximately $50 \%$ of all teacher do consists feedback of acceptance comments (e.g., "okay," "uh-huh"); the findings suggested that male students receive the majority of teacher feedback.

Whether boys actually receive more interaction in the form of praise or criticism is debatable. However, Irvine [26,27] found teacher give less feedback to female students. Hall et al. [25] claim that this sex disparity continued through graduate school.

The study of qualitative study based on ten interviews with graduate students, by Holstrom have concluding similar results; which indicated that female students having the feeling that faculty often did not deal with female graduate students as seriously as their male counterparts. In addition, Schroeder et al. [28] male students are usually meet male professors outside class.

We have identified one contextual factor (school subject), as well as several student factors (classroom behavior, achievement, and race) and two teacher factors (sex and sex-role), that may moderate the relationship between teacher-student interactions and student sex. Undoubtedly, the list of moderating factors influencing sex differences in teacher-student interactions is not exhaustive, but our review suggests that the relationship between student sex and teacher-student interactions may be less clear-cut than it appears to be in some empirical research.

\section{Personal reflection}

According to my personal perspective, students can evaluate the teaching faculty depending on their gender for these reasons. First, the students in my community like the masculine form in many fields except some "feminine" fields like hair dressing and cooking and other women's professions. In Arabic culture, in general, men dominate in all the dimensions that relate to teaching at higher levels such as universities. Second, women, because to this cultural discrimination, tend to focus on having an aggressive presence in most fields. Sometimes this leads women to negatively treat the students, or sometimes to judge the male students harshly and support the female students. This cultural discrimination is very common because families in Arabic culture are built on the idea that men are everything. The thinking is that the man is the only one who can carry the family name and heritage on to the next generation, whereas the name of the women could disappear if the woman marries a "foreign" man, which means he is not from her family. This family oriented discrimination makes female have lower voting power in many fields, not just teaching in an academic field. As I noticed from the above literature review, the favored gender is not consistent as shown in the studies.

\section{Recommendations for Minimizing the Effects of Gender on Student Evaluations of Teachers}

First, the administration should develop workshops to educate about gender influence by designing activities that promote gender awareness, and promote interaction both inside and outside the classroom, also highlighting the connections between student evaluations and professors. For instance, female teachers spend more time in after-class/office consultations than male teachers [6].

Second, encourage students to think critically about these practices and to consider how they could be evaluating faculty unfairly due to pre-formed ideas about members of certain social categories. This will increase gender awareness for individual instructors and raise concerns about gender and evaluation in the classroom [29].

Third, providing special techniques for interpreting student evaluations will improve the level of the evaluation and provide more accurate results free from gender impact.

\section{Conclusion}

The administration should search and collect data on the race/ ethnicity, sexual orientation, and/or social class backgrounds of teachers and/or students to make available the context for the interpretation of their findings. Betsy Lucal and her colleagues note the there is a shortage of information about the influence of race/ ethnicity, social class, and sexual orientation on teaching assessments [30]. The researcher insists that further research on the interaction of these factors is needed.

\section{References}

1. Giegerich S (2004) Women represent majority of college students, minority of tenured faculty and administrators. The Associated Press.

2. Gibbard CS (2004) Mothers in the Faculty Pipeline. Women in Higher Education 13: 16.

3. Virginia V (2005) Equity Resources. Gender Equity Project.

4. Catherine S (1982) Our search and research: The study of women since 1969.

5. CreativeFolk.com (2007) Women's Studies Programs Mailing List.

6. Bennett SK (1982) Student perceptions of and expectations for male and female instructors: evidence relating to the question of gender bias in teaching evaluation. Journal of Educational Psychology 74: 170-179.

7. Downs VC, Downs TM (1993) An exploratory and descriptive study identifying communicative behaviors associated with effective college teaching. Paper presented at the annual meeting of the International Communication Association, Washington, DC.

8. Hutchinson L, Beadle M (1992) Professors' communication styles: How they influence male and female seminar participants. Teaching \& Teacher Education 8: 405-418.

9. Pearson JC, West R (1991) An initial investigation of the effects of gender on student questions in the classroom: Developing a descriptive base. Communication Education 40: 22-32.

10. Sternglanz SH, Lyberger-Ficek S (1977) Sex-differences in student-teacher interactions in the college classroom. Sex Roles 3: 345-352.

11. Peter S (1999) Current practices-good and bad-nationally. In: Seldin P (ed.), Changing Practices in Evaluating Teaching: A Practical Guide to Improved Faculty Performance and Promotion/Tenure Decisions. Anker Publishing, Boston pp: 1-24.

12. Kenneth FA (1993) College students' views of male and female college teachers: Part II-Evidence from students' evaluations of their classroom teachers. Research in Higher Education 34: 151-191. 
13. Kenneth FA (1992) College students' views of male and female college teachers: Part I-Evidence from the social laboratory and experiments. Research in Higher Education 33: 317-375.

14. Freeman HR (1994) Student evaluations of college instructors: Effects of type of course taught, instructor gender and gender role, and student gender. Journal of Educational Psychology 86: 627-630.

15. Virginia W, Potorti P (1989) Student assessment of teacher masculinity and femininity: a test of the sex role congruency hypothesis on student attitudes toward learning. Journal of Educational Psychology 81: 259-262.

16. Julianne A, Williams B (2003) Students perceptions of expressiveness: age and gender effects on teacher evaluations. Sex Roles 49: 507-16.

17. Basow SA, Nancy TS (1987) Student evaluations of college professors: Are female and male professors rated differently? Journal of Educational Psychology 79: 308-314.

18. Basow SA (2000) Best and worst professors: gender patterns in students choices. Sex Roles 43: 407-417.

19. Wilson D, Doyle KO (1976) Student ratings of instruction: Student and instructor sex interactions. Journal ofHigher Education 47: 465-470.

20. Winocur S, Schoen LG, Sirowatka AH (1989) Perceptions of male and female academics within a teaching context. Research in Higher Education 30: 317-329.

21. Hillmann SB, Davenport GG (1978) Teacher-student interactions in desegregated schools. Journal of Educational Psychology 70: 545-553.
22. Becker JR (1981) Differential treatment of females and males in mathematics classes. Journal of Research in Mathematics Education 12: 40-53.

23. She HC (2000) The interplay of a biology teacher's beliefs, teaching practices and gender-based student-teacher interaction. Educational Research 42: 100-111.

24. Sikes JN (1971) Differential behavior of male and female teachers with male and female students. Unpublished doctoral dissertation, University of Texas at Austin.

25. Hall RM, Sandler BR (1984) Out of the classroom: A chilly campus climate for women?. Association of American Colleges, Washington, DC.

26. Irvine JJ (1985) Teacher communication patterns as related to the race and sex of the student. Journal of Educational Research 78: 338-345.

27. Irvine JJ (1986) Teacher-student interactions: Effects of student race, sex, and grade level. Journal of Educational Psychology 78: 14-21.

28. Schroeder DS, Mynatt CR (1999) Graduate students' relationship with their male and female major professors. Sex Roles 40: 393-420.

29. Michael M (2000) White guy habitus in the classroom: challenging the reproduction of privilege. Men and Masculinities 2: 457-469.

30. Jordan FF, McGreal EA, Wheeless VE (1990) Student perceptions of teacher sex-role orientation and use of power strategies and teacher sex as determinants of student attitudes toward learning. Communication Quarterly 38: 43-53. 